\title{
Clinical and radiological follow-up after free vascularised fibula transplantation for bone defects of the upper extremity with MRI and MR- angiography
}

\section{Lisa Eckstein}

Universitatsmedizin Greifswald

\section{Ariane Asmus}

Unfallkrankenhaus Berlin

\section{Sven Mutze}

Unfallkrankenhaus Berlin

\section{Sinan Bakir}

Universitatsmedizin Greifswald

\section{Lyubomir Haralambiev}

Universitatsmedizin Greifswald

Andreas Eisenschenk

Universitatsmedizin Greifswald

Simon Kim ( $\square$ kims@uni-greifswald.de )

Klinik für Unfallchirurgie Greifswald https://orcid.org/0000-0002-7455-7421

Research article

Keywords: Free vascularised fibula graft, MRI, MRI angiography, bone healing score

Posted Date: October 21st, 2019

DOl: https://doi.org/10.21203/rs.2.16274/v1

License: (c) (1) This work is licensed under a Creative Commons Attribution 4.0 International License. Read Full License 


\section{Abstract}

Background Vascular patency of free vascularised fibula grafts can be postoperatively assessed by island flap which is not always possible or angiography which is invasive. Bone healing is examined based on radiographs with scoring systems. We present data on MRI with contrast agent and a comparison of the Giessler bone healing score by X-ray and MRI and clinical scores in patients with operation on the upper extremity.

Methods We reviewed the clinical and radiological outcome of 13 patients with a follow-up of at least 1 year after free vascularised fibula graft of the upper extremity. The examination included the DASH, MSTS, SF-36, Rosén-Lundberg-scores and MRI with contrast agent. We determined the Giessler bone healing score by most recent $\mathrm{x}$-ray and MRI and the Weiland score and its modification for the upper extremity. For statistics, we used the Wilcoxon test and Pearson correlation.

Results Vascular patency was directly or indirectly detectable all cases in the MRI with contrast agent. 5 patients did not return to work and 5 patients had ongoing pain medication. Median DASH was 21.7, MSTS of the upper extremity 76.7, of the lower extremity 93.3, the Rosén-Lundberg score for median nerve 2.43, for ulnar nerve 2.32. Giessler score for x-ray and MRI showed no significant difference for proximal or distal junction.

Conclusions We could prove with MRI that it was indeed a vascularised graft and its vitality at time of follow-up by assessment of vascular patency, and that MRI can be used to determine the Giessler score similarly to X-ray.

\section{Background}

After surgical treatment of osteomyelitis, bone tumours or pseudarthrosis, the resulting bone defect may be filled with a vascularised fibula graft $(1,2)$. This has been shown to be effective for defects of the femoral shaft (3) and after resection of giant cell tumour of the distal radius (4). But compared to the lower limb or shoulder, there less information on free vascularised fibula grafts of the forearm $(5,6)$.

The value of preoperative MRI imaging for identification of the peroneal artery has been shown (7). The postoperative controls usually include plain X-ray for determination of bony consolidation and hypertrophy (7). Postoperative control of vascular patency can be performed by an indicator flap (8) or by angiography.

\section{Methods}

We searched our electronic database for patients who received a free vascularised fibula bone graft for the upper extremity without shoulder between January 2002 and September 2018 in the Universitätsmedizin Greifswald (Germany) and Unfallkrankenhaus Berlin (Germany) and invited them for follow-up with MR-angiography. 
We documented sex, age at follow-up, date of first operation, fibula graft operation and follow-up, indication for fibular graft transplantation, duration of hospitalization, side of operation, hand dominance, complications, occupational status, current pain medication, graft receiving area, donor side, length of graft, type of vascular connection, and type of additional operative procedures.

Clinical examination included range of motion and items for the Rosén-Lundborg-Score (table 1) (9).

We determined the DASH score using the local translation, the MSTS/Enneking-Score, SF-36, and pain at rest and during exercise on a 11 point scale (10-13).

We averaged force grip (Jamar dynamometer), two-point pinch force between tip of thumb and index (Pinchmeter) from three trials alternating between operated and contralateral hand as part of the RosénLundborg-score.

Most recent X-ray images and MRI with and without contrast agent were assessed for bony consolidation, calculation of the bone hypertrophy index after de Boer and Wood, and bone healing using the Giessler modification of the scale published by Taira, the original Weiland score and its modification by Höpfner (14-18).

MRI was assessed for bony consolidation, periosteal fluid accumulation and vascular patency.

Metric values are rounded and shown with median and range as the statistic tests are based on them in addition to mean and standard deviation.

Clinical function comparison was performed using the contralateral hand as control. Here, we present data only for patients with a follow-up of at least 1 year but show imaging of a patient with more recent MRI. Values were rounded according to the relevance of decimals. Due to the small sample size, we used the Wilcoxon-test for comparison of paired quantitative variables. The Pearson correlation coefficient was used to show the degree of linear correlation. Significant differences were assumed for $p<=0.05$.

\section{Results}

We identified 24 patients who received a vascularised fibula graft for the upper extremity. Eleven patients were lost to follow-up. Of the presenting 13 patients, two patients had a contraindication for MRI diagnostics. Two patients had claustrophobia, resulting in $9 \mathrm{MRI}$ examinations.

Table 2 and 3 show information on the nine male and four female patients. Table 4 shows clinical scores at follow-up. Relevant time intervals and age of the patients as well as status of bony consolidation, type of vascular anastomosis, additional procedures, complications, number of follow-up operations are provided in the Tables, Supplemental Digital Content 1-3.

5 patients had ongoing pain medication on follow-up. Under treatment, resting pain of the donor site was median $0(0-2)$, of the receiving site median $0(0-6)$. Patient $4,6,8,12$, and 13 did not return to work. On 
stress, pain of the donor site was median $0(0-5)$ and of the receiving site median $3(0-10)$. Of 11 patients with available follow-up x-ray, three patients ( 5 to 7 ) showed a relevant bone hypertrophy of $>=$ $20 \%$ (41\%, $23 \%$, and $56 \%$ ). Radiographic scores are shown in table 5. In MRI, the susceptibility artefact showed the location of the anastomosis (Fig. 1-3 and Supplemental Digital Content 4-6). A contrasted vessel next to that artefact represented the fibular artery which was seen in eight of nine patients. One patient with undetectable fibular artery showed early venous contrast enhancement (Fig. 4 and Supplemental Digital Content 7). This was considered to show open anastomoses from artery through graft to vein.

\section{Discussion}

We could show direct or indirect patency of the vessels supplying the fibula grafts in MRI. Therefore, we can conclude that it was indeed a vascularised graft in all cases. The advantages over non-vascularised grafts are assumed to include more rapid healing, reduction of non-union, fatigue fracture and infection $(17,19)$.

For postoperative monitoring of the vascularity, scintigraphy has been used but may give false-positive results (20-22). Angiography or indicator flaps are other possible methods $(8,23)$. In cases of arterial interposition, doppler analysis of blood flow distally would prove patency of the anastomosis (24). Biopsy of live osteocytes is an invasive method that shows viability of the graft $(22,25)$.

In a postoperative angiographic control of vascular patency at 13.9 weeks, 3 out of 74 patients showed a occlusion of the anastomosis (26). Angiography up to six weeks postoperatively were performed by Moore and Weiland but not continued due to potential morbidity $(19,25)$. Additionally, the radiation dose would not permit frequent repeats of the angiography.

Viability of the graft is assumed in cases with evident union (27). It is assumed that bony union will occur within 12 months when vascularity is retained (28). But this was not yet proven. In children, failure of revascularization would lead to premature fusion of the growth plate (29).

Compared to conventional angiography, MRI offers a radiation free tool. The postoperative confirmation of vascular patency in addition to conventional x-ray would help decide on the treatment regarding load bearing, especially after further revision operations. Further advantages include the possibility of retrospective assessment of imaging data which may not be given for ultrasound examinations in all cases.

Complications can range up to $52 \%$ in fibula grafting for tumour resection $(30,31)$.

The low number of hypertrophies in the upper extremity is consistent with previous findings. In a study with 21 humeral and 12 forearm reconstructions, no bone hypertrophy was seen after one year follow up (26). Solid consolidation may not always appear at one junction which was explained by occlusion of blood outflow, which convert the fibula into an end-organ $(24,26,27)$. Sparks et al. discussed that a 
fibula, that was osteotomized on several sides and lost its periosteum, may show decreased or arrested perfusion, resulting in resorption and patchy necrosis (32).

Weakness of extensor hallucis longus was reported as intermittent donor site complication $(4,33)$, but did not appear in our series.

In a study with 32 patients who had an average defect of $12 \mathrm{~cm}$ with a follow-up of 5 months to 14.6 years, six received a fibular graft of the radius and three of the humerus (33). They found a hypertrophy in three out of six fibulas in the upper limb and a not significant lower degree of hypertrophy compared to the lower limb. That study did not report functional outcomes, and complications were given in total. But results can vary a lot regarding clinical outcome and bony union (34).

\section{Conclusions}

MRI with contrast agent is a radiation free tool for postoperative and follow-up evaluation of free vascularised fibula grafts. It can be used to determine the bone healing score

\section{Declarations}

Ethics approval and consent to participate

The local institutional ethics committee of the University of Greifswald approved the study (BB 119/18) and stated that there are no ethical or legal concerns regarding this study. The decision was based on the Helsinki declaration. The institutional ethics committee approved the study (BB119/18).

Consent for publication

We obtained written consent from all patients who presented for follow-up for publication of research data, including radiographic data.

Availability of data and materials

The datasets used and/or analysed during the current study are available from the corresponding author on reasonable request.

Competing interests

The authors declare that they have no conflict of interest.

Funding

No funding was received

Author Contribution 
LE Project development, Data collection, Data analysis, Data interpretation, Manuscript writing

AA Project development, Data collection, Data analysis, Manuscript editing

SM Data collection, Data analysis, Data interpretation, Manuscript editing

SB Data analysis, Data interpretation, Manuscript editing

LH Data analysis, Data interpretation, Manuscript editing

AE Project development, Data collection, Manuscript editing

SK Project development, Data management, Data analysis and interpretation, Manuscript writing

All authors have read and approved the manuscript.

Acknowledgements

Not applicable

\section{References}

1.Sun Y, Zhang C, Jin D, Sheng J, Cheng X, Liu X, et al. Free vascularised fibular grafting in the treatment of large skeletal defects due to osteomyelitis. Int Orthop. 2010;34(3):425-30.

2.Azi ML, Aprato A, Santi I, Kfuri M, Jr., Masse A, Joeris A. Autologous bone graft in the treatment of posttraumatic bone defects: a systematic review and meta-analysis. BMC Musculoskelet Disord. 2016;17(1):465.

3.Jupiter JB, Bour CJ, May JW, Jr. The reconstruction of defects in the femoral shaft with vascularized transfers of fibular bone. J Bone Joint Surg Am. 1987;69(3):365-74.

4.Saini R, Bali K, Bachhal V, Mootha AK, Dhillon MS, Gill SS. En bloc excision and autogenous fibular reconstruction for aggressive giant cell tumor of distal radius: a report of 12 cases and review of literature. J Orthop Surg Res. 2011;6:14.

5.Cano-Luis P, Andres-Cano P, Ricon-Recarey FJ, Giraldez-Sanchez MA. Treatment of posttraumatic bone defects of the forearm with vascularized fibular grafts. Follow up after fourteen years. Injury. 2018;49 Suppl 2:S27-S35.

6.Adani R, Delcroix L, Innocenti M, Marcoccio I, Tarallo L, Celli A, et al. Reconstruction of large posttraumatic skeletal defects of the forearm by vascularized free fibular graft. Microsurgery. 2004;24(6):423-9. 
7.Manaster BJ, Coleman DA, Bell DA. Pre- and postoperative imaging of vascularized fibular grafts. Radiology. 1990;176(1):161-6.

8.Yoshimura M, Shimamura K, Iwai Y, Yamauchi S, Ueno T. Free vascularized fibular transplant. A new method for monitoring circulation of the grafted fibula. J Bone Joint Surg Am. 1983;65(9):1295-301.

9.Rosen B, Lundborg G. A model instrument for the documentation of outcome after nerve repair. J Hand Surg Am. 2000;25(3):535-43.

10.Kurth BM, Ellert U. The SF-36 questionnaire and its usefulness in population studies: results of the German Health Interview and Examination Survey 1998. Soz Praventivmed. 2002;47(4):266-77.

11.Ellert U, Kurth BM. [Methodological views on the SF-36 summary scores based on the adult German population]. Bundesgesundheitsblatt Gesundheitsforschung Gesundheitsschutz. 2004;47(11):1027-32.

12.Germann G, Harth A, Wind G, Demir E. [Standardisation and validation of the German version 2.0 of the Disability of Arm, Shoulder,Hand (DASH) questionnaire]. Unfallchirurg. 2003;106(1):13-9.

13.Enneking WF, Dunham W, Gebhardt MC, Malawar M, Pritchard DJ. A system for the functional evaluation of reconstructive procedures after surgical treatment of tumors of the musculoskeletal system. Clin Orthop Relat Res. 1993(286):241-6.

14.de Boer $\mathrm{HH}$, Wood MB. Bone changes in the vascularised fibular graft. J Bone Joint Surg Br. 1989;71(3):374-8.

15.Asmus A, Kim S, Höpfner J-I, Vogel A, Vogel K, Eichenauer F, et al. Freie Fibulatransplantation zur knöchernen Rekonstruktion an der oberen Extremität. Handchir Scan. 2018;07(03):231-42.

16.Höpfner J-I. Klinische und radiologische Langzeitergebnisse nach freier, vaskularisierter Knochentransplantation zur Überbrückung großer Defekte der langen Extremitätenknochen 2003.

17.Weiland AJ, Phillips TW, Randolph MA. Bone grafts: a radiologic, histologic, and biomechanical model comparing autografts, allografts, and free vascularized bone grafts. Plast Reconstr Surg. 1984;74(3):368-79.

18.Giessler GA, Zobitz M, Friedrich PF, Bishop AT. Transplantation of a vascularized rabbit femoral diaphyseal segment: mechanical and histologic properties of a new living bone transplantation model. Microsurgery. 2008;28(4):291-9.

19.Moore JR, Weiland AJ, Daniel RK. Use of free vascularized bone grafts in the treatment of bone tumors. Clin Orthop Relat Res. 1983(175):37-44.

20.Canosa R, Gonzalez del Pino J. Effect of methotrexate in the biology of free vascularized bone grafts. A comparative experimental study in the dog. Clin Orthop Relat Res. 1994(301):291-301. 
21.Shaffer JW, Field GA, Wilber RG, Goldberg VM. Experimental vascularized bone grafts: histopathologic correlations with postoperative bone scan: the risk of false-positive results. J Orthop Res. 1987;5(3):3119.

22. Hirayama T, Suematsu N, Inoue K, Baitoh C, Takemitsu Y. Free vascularised bone grafts in reconstruction of the upper extremity. J Hand Surg Br. 1985;10(2):169-75.

23.Gidumal R, Wood MB, Sim FH, Shives TC. Vascularized bone transfer for limb salvage and reconstruction after resection of aggressive bone lesions. J Reconstr Microsurg. 1987;3(3):183-8.

24.Dell PC, Sheppard JE. Vascularized bone grafts in the treatment of infected forearm nonunions. J Hand Surg Am. 1984;9(5):653-8.

25.Weiland AJ, Kleinert HE, Kutz JE, Daniel RK. Free vascularized bone grafts in surgery of the upper extremity. J Hand Surg Am. 1979;4(2):129-44.

26.Eisenschenk $A$, Lautenbach $M$, Rohlmann A. [Free vascularized bone transplantation in the extremities]. Orthopade. 1998;27(7):491-500.

27.El-Sherbiny M. Reconstruction of the proximal humerus after wide resection of tumors: comparison of three reconstructive options. J Egypt Natl Canc Inst. 2008;20(4):369-78.

28.Erol B, Basci O, Topkar MO, Caypinar B, Basar H, Tetik C. Mid-term radiological and functional results of biological reconstructions of extremity-located bone sarcomas in children and young adults. J Pediatr Orthop B. 2015;24(5):469-78.

29.Innocenti M, Delcroix L, Balatri A. Vascularized growth plate transfer for distal radius reconstruction. Semin Plast Surg. 2008;22(3):186-94.

30.Fuchs B, O'Connor MI, Padgett DJ, Kaufman KR, Sim FH. Arthrodesis of the shoulder after tumor resection. Clin Orthop Relat Res. 2005(436):202-7.

31.Gebert C, Hillmann A, Schwappach A, Hoffmann C, Hardes J, Kleinheinz J, et al. Free vascularized fibular grafting for reconstruction after tumor resection in the upper extremity. J Surg Oncol. 2006;94(2):114-27.

32.Sparks DS, Saleh DB, Rozen WM, Hutmacher DW, Schuetz MA, Wagels M. Vascularised bone transfer: History, blood supply and contemporary problems. J Plast Reconstr Aesthet Surg. 2017;70(1):1-11.

33.Falder S, Sinclair JS, Rogers CA, Townsend PL. Long-term behaviour of the free vascularised fibula following reconstruction of large bony defects. Br J Plast Surg. 2003;56(6):571-84.

34.Repo JP, Sommarhem A, Roine RP, Sintonen H, Halonen T, Tukiainen E. Free Vascularized Fibular Graft is Reliable in Upper Extremity Long-Bone Reconstruction with Good Long-Term Outcomes. J Reconstr 
Microsurg. 2016;32(7):513-9.

\section{Tables}

Table 1: Items of the Rosén-Lundborg-Score

\begin{tabular}{|c|c|}
\hline $\begin{array}{l}\text { Rosén-Lundberg-Score } \\
\text { Item }\end{array}$ & Description \\
\hline Sensory innervation & Semmes-Weinstein monofilaments according to Bell-Krotoski \\
\hline \multirow[t]{2}{*}{ Tactile Gnosis } & 2-point discrimination according to Moberg \\
\hline & $\begin{array}{l}\text { Shape/texture identification (STI) according to Rosén and } \\
\text { Lundborg }\end{array}$ \\
\hline Finger Dexterity & Sollerman hand function test, tasks 4,8 , and 10 \\
\hline Motor Innervation & Manual muscle strength, MRC muscle power grading \\
\hline Grip Strength & Jamar dynamometer according to Mathiowetz \\
\hline Pain & 4 grade scale for hyperesthesia and cold intolerance \\
\hline $\begin{array}{l}\text { Patient's Opinion of } \\
\text { Recovery }\end{array}$ & Impact on ADL on a visual analog scale \\
\hline Scale of Sensory Recovery & $\begin{array}{l}\text { Modification by Mackinnon and Dellon of the } \\
\text { Medical Research Council proposal }\end{array}$ \\
\hline
\end{tabular}

Table 2 Preoperative status 


\begin{tabular}{|c|c|c|c|c|c|}
\hline & Preoperative history & Indication & Side & Dominant & $\begin{array}{c}\text { Preoperative } \\
\text { nerve lesion }\end{array}$ \\
\hline $\mathbf{1}$ & Distal radius fracture & osteomyelitis & right & yes & \\
\hline $\mathbf{2}$ & $\begin{array}{c}\text { Chronic osteomyelitis and soft } \\
\text { tissue infection due to iv drug }\end{array}$ & osteomyelitis & right & yes & Median, ulnar, \\
radial
\end{tabular}

Table 3 Information on operation. 


\begin{tabular}{|r|c|c|c|}
\hline & Receiving site & Donor site & Length of graft [cm] \\
\hline $\mathbf{1}$ & Radius & contralateral & 5 \\
\hline $\mathbf{2}$ & Radius+Ulna & contralateral & 5 \\
\hline $\mathbf{3}$ & Radius+Ulna & ipsilateral & 15.5 \\
\hline $\mathbf{4}$ & Radius & ipsilateral & 8.5 \\
\hline $\mathbf{5}$ & Radius & contralateral & 7.5 \\
\hline $\mathbf{6}$ & Humerus & ipsilateral & 16 \\
\hline $\mathbf{7}$ & Ulna & ipsilateral & 6 \\
\hline $\mathbf{8}$ & Radius & contralateral & 5 \\
\hline $\mathbf{9}$ & Ulna & contralateral & 8 \\
\hline 10 & Radius & contralateral & 8 \\
\hline $\mathbf{1 1}$ & Radius & contralateral & 4.5 \\
\hline 12 & Radius/Wrist & ipsilateral & 12.5 \\
\hline 13 & Ulna & ipsilateral & 5 \\
\hline & & & \\
\hline
\end{tabular}

Patient 2 and 3 received the fibula graft for the construction of a one bone forearm.

Table 4 Functional scores 


\begin{tabular}{|c|c|c|c|c|c|}
\hline & median & range & mean & SD & $\mathbf{n}$ \\
\hline DASH & 21.7 & $0-55$ & 23.3 & 17.5 & 11 \\
\hline $\begin{array}{l}\text { MSTS/Enneking upper extremity in \% of } \\
\text { maximum }\end{array}$ & 76.7 & $15-100$ & 73.5 & 23.7 & 11 \\
\hline $\begin{array}{l}\text { MSTS/Enneking lower extremity in } \% \text { of } \\
\text { maximum }\end{array}$ & 93.3 & $29-100$ & 87.8 & 19.3 & 11 \\
\hline SF-36 mental component & 50.96 & $\begin{array}{r}14.69- \\
63.45\end{array}$ & & & \\
\hline SF-36 physical component & 41.87 & $\begin{array}{r}29.87- \\
59.98\end{array}$ & & & \\
\hline Rosén-Lundberg sensory median & 0.86 & $0.45-1.00$ & 0.83 & 0.16 & 13 \\
\hline Rosén-Lundberg sensory ulnar & 0.85 & $0.43-1.00$ & 0.83 & 0.17 & 13 \\
\hline Rosén-Lundberg motor median & 0.58 & $0.00-0.99$ & 0.58 & 0.30 & 11 \\
\hline Rosén-Lundberg motor ulnar & 0.50 & $0.20-0.99$ & 0.59 & 0.25 & 11 \\
\hline Rosén-Lundberg pain/discomfort & 1.00 & $0.50-1.00$ & 0.94 & 0.14 & 13 \\
\hline Rosén-Lundberg total median & 2.43 & $1.70-2.95$ & 2.39 & 0.42 & 11 \\
\hline Rosén-Lundberg total ulnar & 2.32 & $1.67-2.94$ & 2.36 & 0.42 & 11 \\
\hline Rosén-Lundberg sensory median control & 0.97 & $0.88-1.00$ & 0.95 & 0.04 & 13 \\
\hline Rosén-Lundberg sensory ulnar control & 0.98 & $0.90-1.00$ & 0.96 & 0.03 & 13 \\
\hline
\end{tabular}

For motor function, patient 6 and 12 were excluded as one has a wrist arthrodesis and the other a fibula graft operation for defect of the humerus. 
Table 5 Radiographic scores

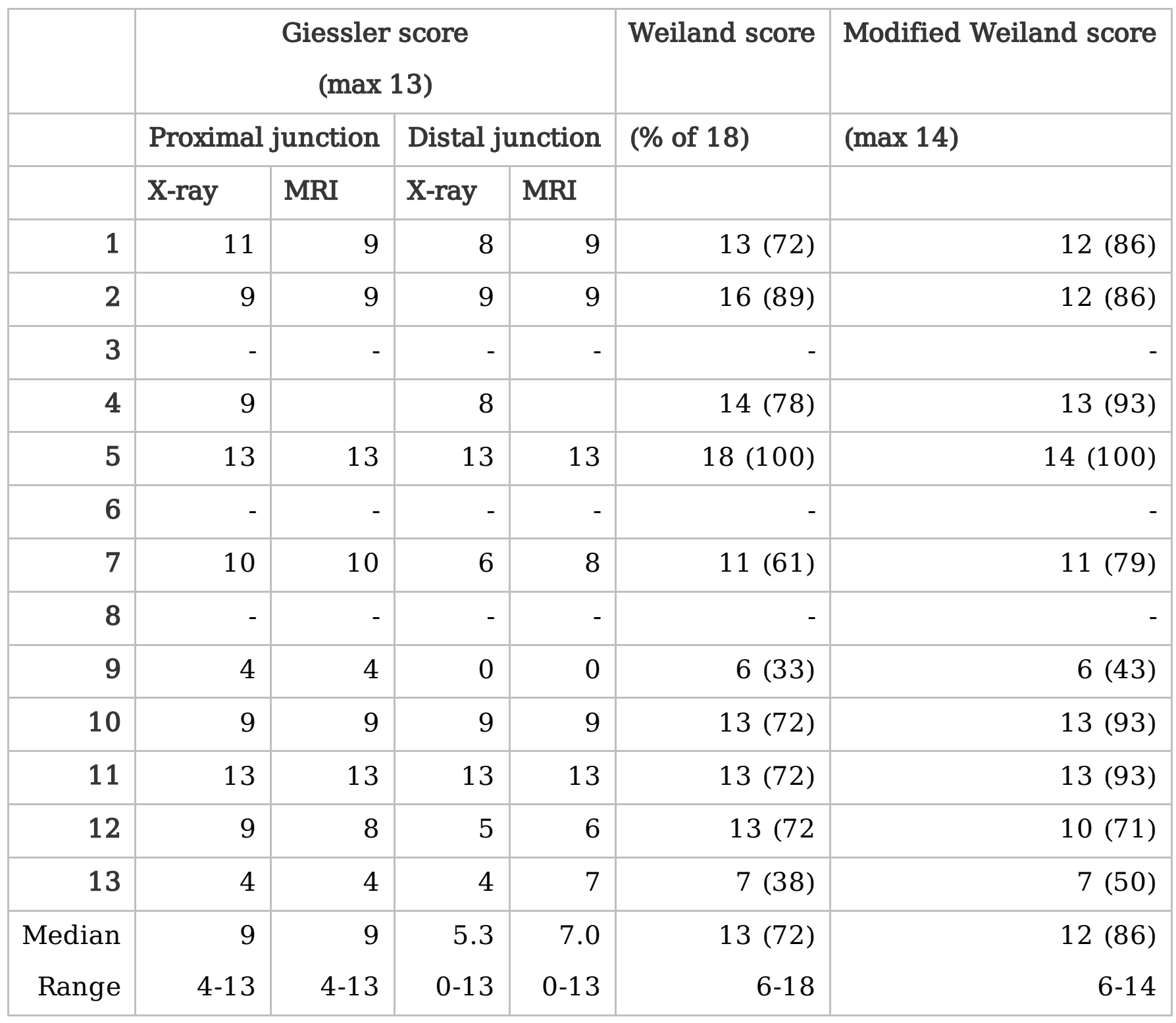

Statistical comparison of the Giessler score between x-ray and MRI showed no difference proximally ( $n=9, p=0.180$, Wilcoxon-test) and distally ( $n=9, p=0.066$, Wilcoxon-test).

Normalised Weiland score and modified Weiland score show a significant difference $(n=10$, $\mathrm{p}=0.021$, Wilcoxon-test) but are linearily correlated $(\mathrm{r}=0.900, \mathrm{p}<0.001$, Pearson correlation test).

\section{Figures}




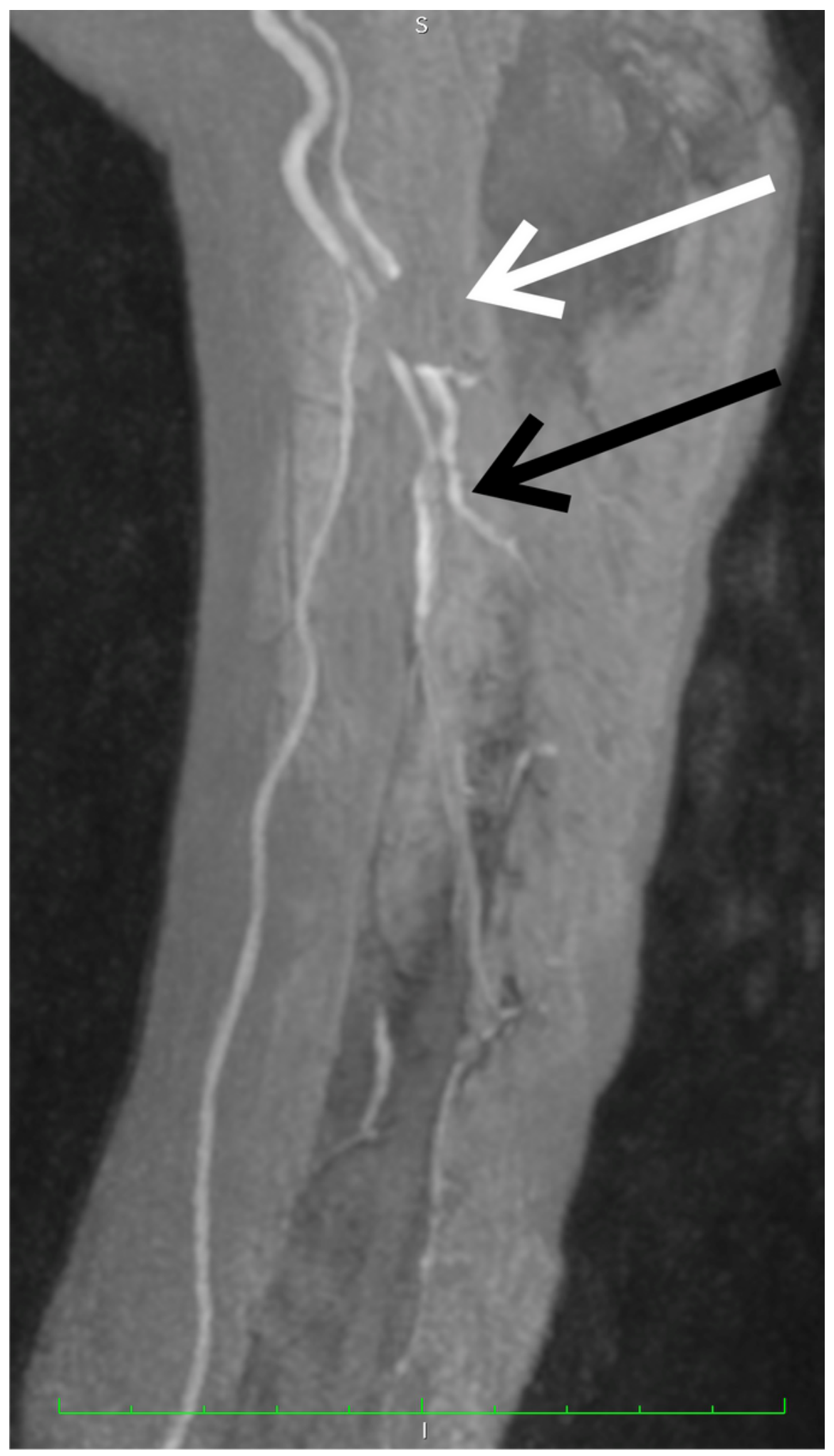

\section{Figure 1}

Example for susceptibility artefact and anastomosis of ulnar and fibular artery The white arrow points at the susceptibility artefact at the anastomosis of ulnar artery and fibular artery (black arrow). A video showing the rotating forearm is available as Supplemental Digital Content 4. 


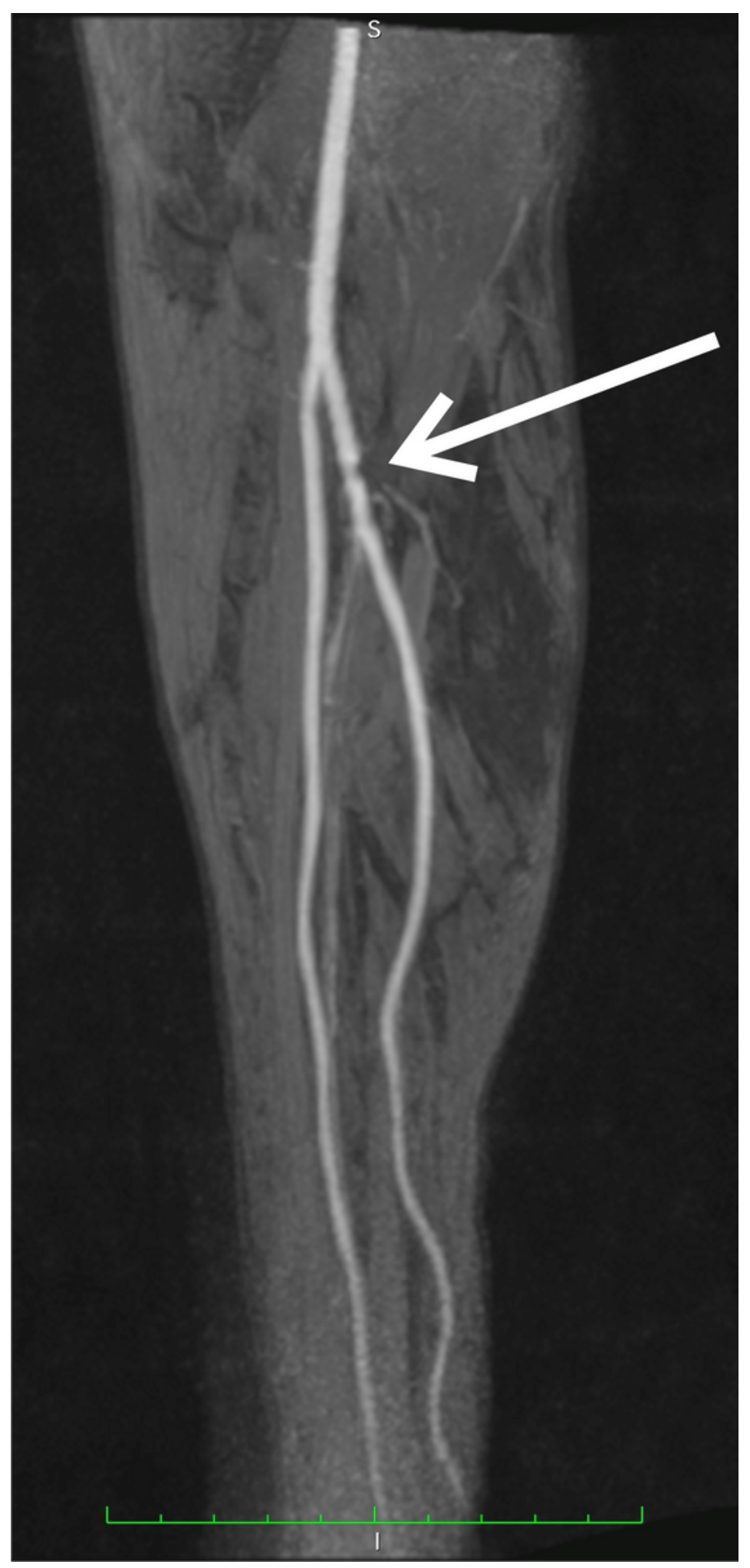

\section{Figure 2}

Second example for susceptibility artefact and anastomosis of ulnar and fibular artery The white arrow is pointed at the susceptibility artefact at the anastomosis of ulnar artery and fibular artery. A video showing the rotating forearm is available as Supplemental Digital Content 5. 


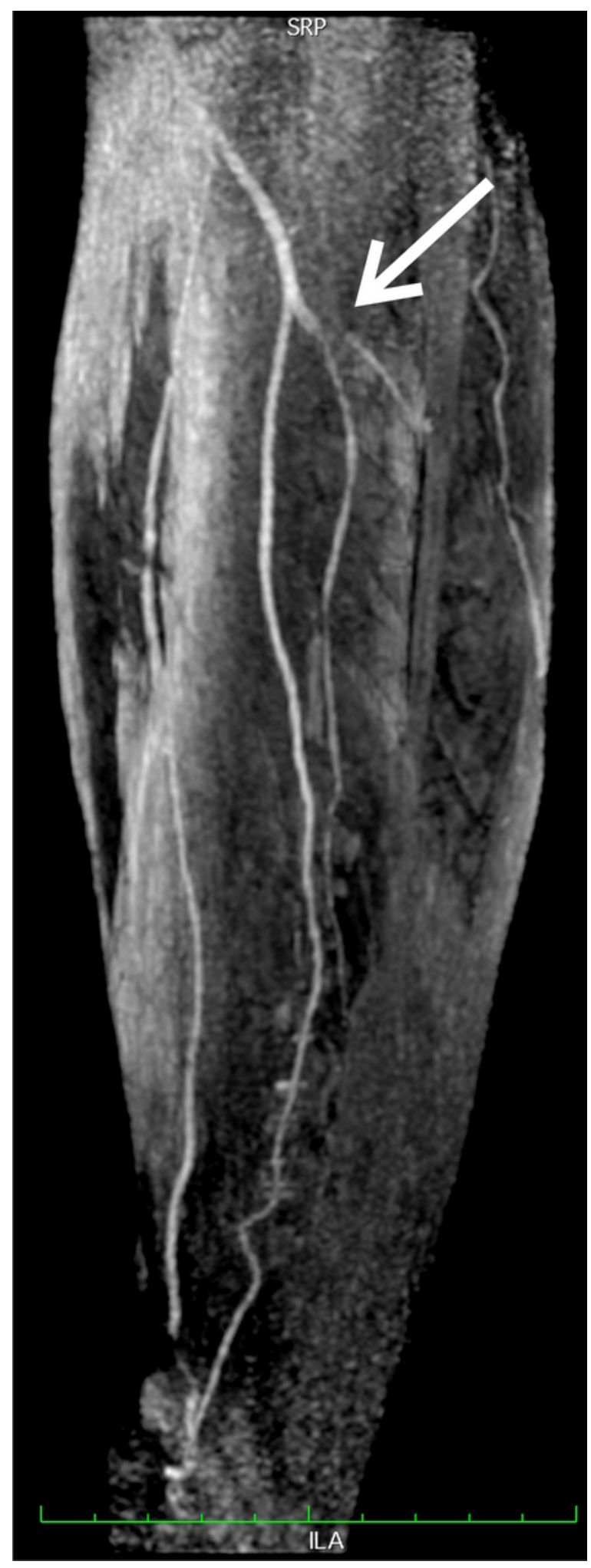

\section{Figure 3}

Example for susceptibility artefact and anastomosis of radial and fibular artery The white arrow points at the susceptibility artefact at the anastomosis of radial artery and fibular artery. A video showing the rotating forearm is available as Supplemental Digital Content 6. 


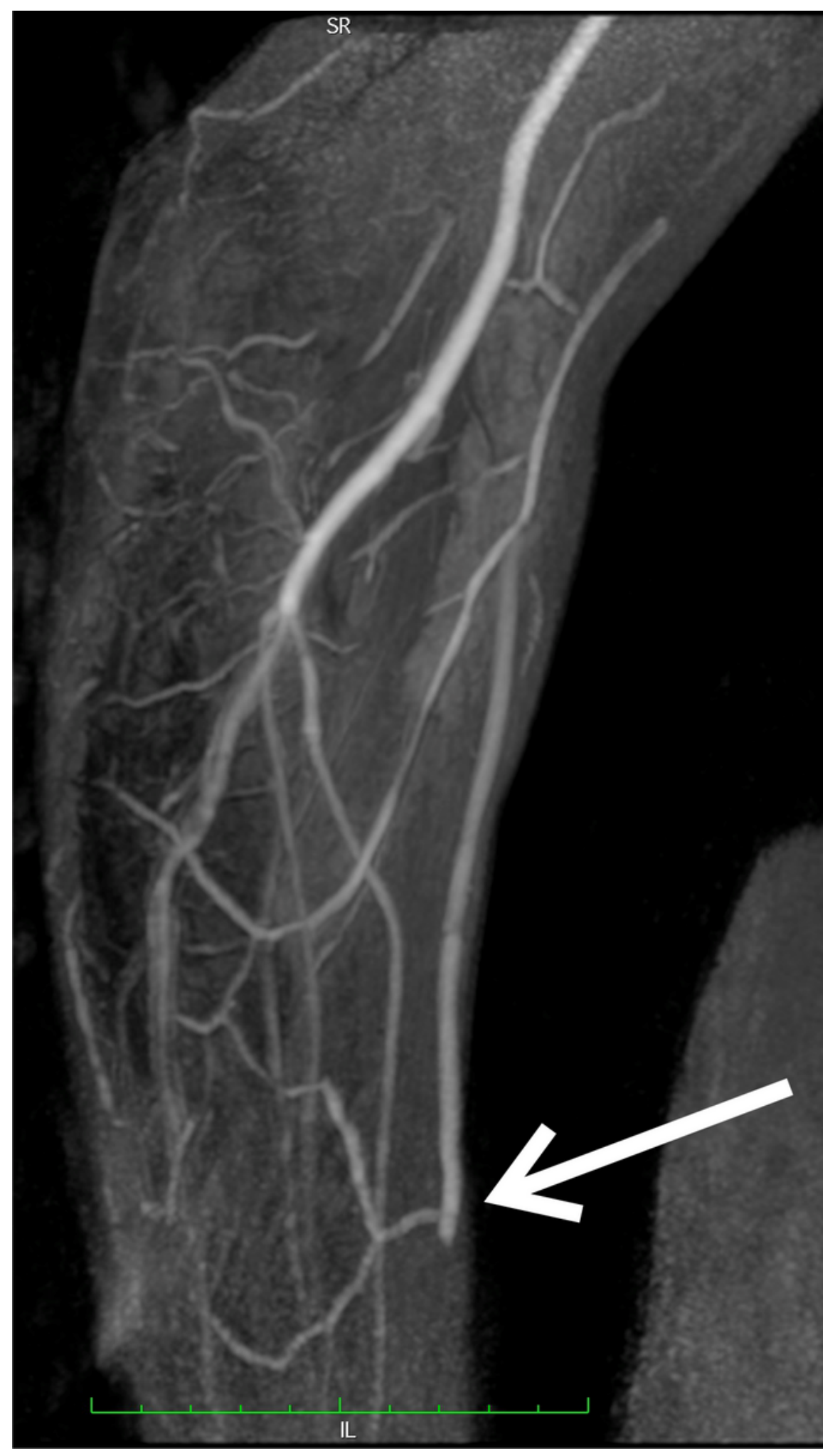

\section{Figure 4}

Early retrograde filling of a subcutaneous vein Example for early retrograde filling of a subcutaneous vein with branches originating at the graft site. A video showing the rotating forearm is available as Supplemental Digital Content 7.

\section{Supplementary Files}


This is a list of supplementary files associated with this preprint. Click to download.

- Additionalfile7.mp4

- Additionalfile4.mp4

- Additionalfile5.mp4

- Additionalfile2.docx

- Additionalfile1.docx

- Additionalfile6.mp4

- Additionalfile3.docx 